\title{
Predictive Algorithms in the Delivery of Public Employment Services
}

\author{
John Körtner* $\quad$ Giuliano Bonoli ${ }^{\dagger}$ \\ June 1, 2022 \\ Prepared for the \\ Research Handbook of Labour Market Policy in Rich Democracies, \\ D. Clegg and N. Durazzi (eds.), Edward Elgar Publishing.
}

\begin{abstract}
With the growing availability of digital administrative data and the recent advances in machine learning, the use of predictive algorithms in the delivery of labour market policy is becoming more prevalent. In public employment services (PES), predictive algorithms are used to support the classification of jobseekers based on their risk of long-term unemployment (profiling), the selection of beneficial active labour market programs (targeting), and the matching of jobseekers to suitable job opportunities (matching). In this chapter, we offer a conceptual introduction to the applications of predictive algorithms for the different functions PES have to fulfil and review the history of their use up to the current state of the practice. In addition, we discuss two issues that are inherent to the use of predictive algorithms: algorithmic fairness concerns and the importance of considering how caseworkers will interact with algorithmic systems and make decisions based on their predictions.
\end{abstract}

\footnotetext{
*IDHEAP, University of Lausanne. E-mail: john.kortner@unil.ch.

IDHEAP, University of Lausanne.
} 


\section{Introduction}

At the centre of labour market policy activities in most modern welfare states are public employment services (PES) and their caseworkers, who enforce labour market policies on the street-bureaucratic level. A central theme in recent reforms of PES has been the use of digital technologies (Weishaupt, this volume) and particularly artificial intelligence (AI) is said to deliver a shift in the way PES work (e.g., Desiere and Struyven, 2021).

The group of algorithms from the field of AI that get particularly much attention for the delivery of services in PES are algorithms that make predictions (e.g., Desiere et al., 2019). These 'predictive algorithms' use statistical or supervised machine learning models to support decisions that hinge on predictions otherwise implicitly made by humans (Kleinberg et al., 2018). In PES, caseworkers have to make predictions when classifying jobseekers into groups based on their risk of long-term unemployment (profiling), when selecting beneficial active labour market programs to help with re-entry into the labour market (targeting), or when matching jobseekers to suitable job opportunities (matching). Improving the predictions (of unemployment duration, the effect of a program, or the likelihood of a job match) with algorithms can allow caseworkers to make better decisions and support them in helping jobseekers. The use of predictive algorithms has therefore long been seen as an attractive option for PES to increase efficiency and standardization across local offices, and the first projects that aimed to predict unemployment outcomes started in the early 1990s (Hasluck, 2008). The recent advances in machine learning have inspired renewed interest in predictive algorithms for the delivery of employment services since machine learning offers the potential to leverage the extensive administrative datasets increasingly available to PES in most countries to make more accurate predictions (Van Landeghem et al., 2021).

In this chapter, we offer an introduction to predictive algorithms. We highlight what makes predictive algorithms distinct from other usages of statistics in the social and policy sciences and discuss why methods from machine learning are promising to improve them. Thereafter, we review applications for the various functions PES have to fulfil: profiling, targeting, and matching. Matching jobs and jobseekers, as well as targeting jobseekers with activating or supporting services are among the main functions of PES (Schwanse, 1997). Profiling is a way 
to support the other two functions. The identification of jobseekers who are at risk of long-term unemployment allows caseworkers to focus efforts on them early on.

In addition, we discuss two issues that are inherent to the use of predictive algorithms: algorithmic fairness and the interaction of caseworkers and predictive algorithms. Across policy domains, the use of predictive algorithms is accompanied by concerns that they reproduce and reinforce existing discrimination against protected groups (Mitchell et al., 2021). We provide a brief review of the general debate on algorithmic fairness and relate it to the labour market context in which predictive algorithms for PES operate in. Understanding the interaction between caseworkers and predictive algorithms is important, as the ultimate choice and responsibility for decisions as well as the interaction with jobseekers remain with the caseworkers and not the algorithms. We use insights from the literature on street-level bureaucracy (Lipsky, 1980; Zacka, 2018) to discuss selected observations from the field.

The overall aim of this chapter is to highlight important concepts for the emerging research field on predictive algorithms in PES and mark it in the broader debate on digitalization and AI. If we had been given more space in this handbook, we would also have discussed important issues like privacy, transparency, and accountability. We conclude the chapter by highlighting that predictive algorithms offer an opportunity for policy researchers to bring their knowledge into practice. The beneficial application of predictive algorithms requires, however, a better understanding of the role of caseworkers and the way they interact with algorithmic systems and make decisions based on their predictions.

\section{Predictive algorithms}

A diverse set of digital technologies are transforming the way PES work and provide access to services. Particular interest surrounds technologies that are driven by AI (e.g., Desiere and Struyven, 2021). In recent years, much progress in AI was made by algorithms that learn from data to make predictions (e.g., Hofman et al., 2017; Agrawal et al., 2018). We will use the term 'predictive algorithm' to denote them in this chapter. Figure 1 provides a visualization of the basic setup (based on Lipton, 2016). 
The main component is a model that can be used to make predictions of outcomes not yet known. To build such a model, historical data are used. ${ }^{1}$ The historical data contain the outcome of interest (also called label, target variable, or dependent variable) that reflects what should be predicted and implies the objective of the algorithm. In PES, this could be e.g., long-term unemployment, or labour market re-entry, or another labour market outcome.

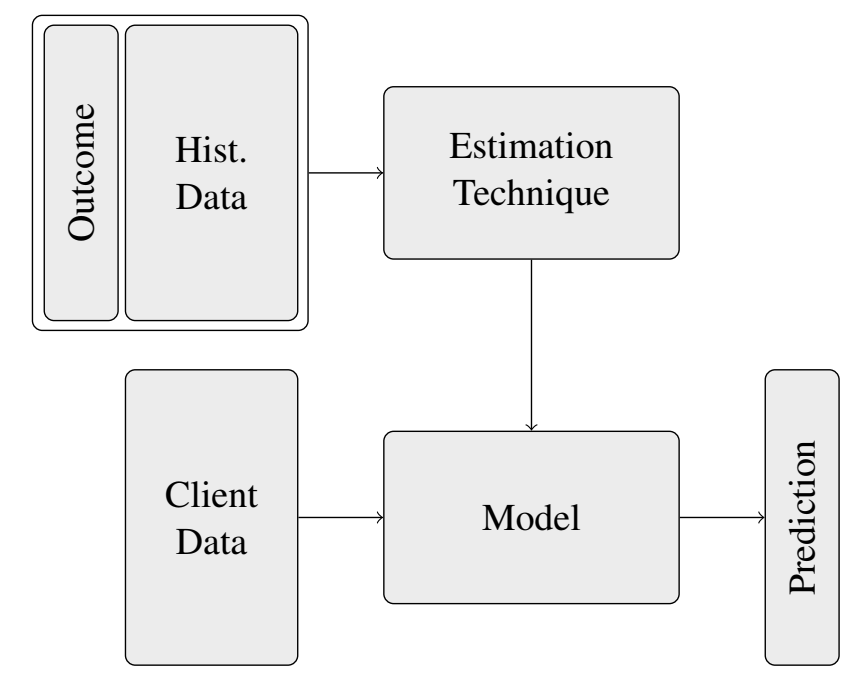

Figure 1: The basic setup of a predictive algorithm. A model is estimated to predict an outcome from relationships in historical data. The model can then be applied to new client data to make predictions for outcomes not yet known.

The historical data are leveraged to estimate (this step is also called training) a model that predicts the outcome from other variables in the historical data (also called features, predictors, or independent variables). In PES, these variables can contain information on education, job tenure, occupation, and socio-demographics from administrative sources, additional personal information from surveys filled out during a counselling meeting, and economic indicators such as the unemployment rate. Once the model is estimated, it can be used to make predictions using new data (from incoming clients) of outcomes not yet known, or of potential outcomes under different hypothetical interventions. ${ }^{2}$

\footnotetext{
${ }^{1}$ Predictions in PES can also be made with rule-based algorithms where the relationship between inputs and outcome is not learned but explicitly programmed (see Desiere et al., 2019). While rule-based algorithms share many of the same properties and issues, the focus of this chapter are algorithms that 'learn' from data.

${ }^{2} \mathrm{~A}$ visualisation of a setup with several models for potential outcomes under different hypothetical interventions similar to figure 1 is in Ferwerda et al. (2020).
} 
Predictive algorithms are distinct from other usages of statistical modelling for the purpose of explanation (Breiman, 2001; Shmueli, 2010) that are widely used in the social and policy sciences. The focus is not on the unbiased estimation of model coefficients but on predictive accuracy. This focus makes it attractive to look at approaches from the field of machine learning, 'supervised' machine learning to be specific, that revolve around prediction. The appeal of supervised machine learning is that it manages to uncover complex patterns in historical data and estimates models that work well out-of-sample, i.e., on data that the model has not seen during the estimation. Machine learning does not require that relationships between two variables are interpretable through a single coefficient and therefore more complex model forms than the traditional linear and generalized linear models can be used, such as neural networks, random forests, ensembles, and their many variants (see e.g., Mullainathan and Spiess, 2017, for a review). A lot of the recent interest in predictive algorithms in PES is driven by the promise of predictive accuracy of these models from machine learning (Van Landeghem et al., 2021).

\section{Predictive algorithms for profiling, targeting, and matching: from early developments to the state of the practice}

In PES, several functions require the use of predictions (see Loxha and Morgandi, 2014, for an overview). We focus on three functions that involve predictions of clients' outcomes: profiling, targeting, and matching. Profiling was the first function for which the use of predictive algorithms was tested, in the early 1990s (Hasluck, 2008). The intention of profiling was already to allow for a better allocation of interventions, so targeting (the prediction of program effectiveness), came shortly after. The use of predictive algorithms for matching, the third function we will discuss, is still relatively unexplored within PES.

\subsection{Profiling}

In profiling, PES classify the population of jobseekers, typically into 'high-risk' and 'lowrisk' with regards to long-term unemployment. The objective is to identify jobseekers with the highest risk of becoming long-term unemployed, so that caseworkers can concentrate their efforts on helping these jobseekers early on. Caseworker often make the judgment of who is 
at risk based on intuition. Predictive algorithms can support them by estimating a score for the expected duration of unemployment or another measure of a labour market outcome reflecting what the specific PES aims for. Thresholds along the score can then be used to directly support the classification decisions, or caseworkers can consider the prediction among other factors for their allocation of attention.

The first known cases of profiling with predictive algorithms were developed as part of the Worker Profiling and Reemployment Service (WPRS) in the US (Wandner et al., 1999) and the Job Seeker Classification Instrument (JSCI) in Australia (Lipp, 2005). Since then, PES in many countries implemented or attempted to implement profiling systems with predictive algorithms (see e.g., Barnes et al., 2015; Desiere et al., 2019; Griffin et al., 2020, for recent reviews). Most of the PES use a measure of long-term unemployment as the outcome variable, varying from 6 to 26 months, with 12 months being the most common choice (as reported by Desiere et al., 2019). In the US, PES use the exhaustion of unemployment insurance benefits as the dependent variable, or the fraction of benefits claimed in PES in some states (Black et al., 2003). On the predictor side, data from administrative sources is used containing information on e.g., education, job tenure, occupation, and socio-demographics. In addition, some PES use questionnaires in the beginning of the process to acquire information on skills and the jobseeker's behaviour (see Bimrose et al., 2007; Blázquez, 2014, for reviews). Economic indicators such as the unemployment rate or other labour market indicators are sometimes used to measure the state of the economy or the sector the jobseeker is searching in.

The most common model choice is logistic regression, however, recent projects started to use more complex model forms: De Troya et al. (2018) test random forest and boosting approaches for Portugal, a system by the PES of the Belgian region of Flanders (VDAB) is implemented using a random forest approach (Desiere and Struyven, 2021), Pôle Emploi in France is reported to work on a system using artificial neural networks (reported in Griffin et al., 2020), a system based on a neural network approach for survival analysis is developed for Slovenia (Boškoski et al., 2021), and Kern et al. (2021) compare (penalized) logistic regressions, random forest and gradient boosting approaches for Germany. 
Black et al. (2007) find that profiling (the WPRS program) reduced the duration of jobseekers in the unemployment insurance system. Arni and Schiprowski (2015) find a positive effect of profiling on the probability to leave unemployment in the first 3, 6 and 9 months for jobseekers where the profiling score was more optimistic than the prediction of the caseworkers. Most other projects did not publish effects on labour market outcomes.

\subsection{Targeting}

The objective of targeting systems is to assign jobseekers to programmes that are beneficial to them. The support of targeting decisions is, in fact, the motivation for many profiling systems, though estimating the expected effect of an intervention is different than predicting the risk of long-term unemployment (Berger et al., 2001). Targeting systems require the estimation of potential outcomes to answer what the expected effect of an intervention would be (see also Frölich et al., 2003; Frölich, 2008). The strategy reflecting this is to predict the expected outcome of each possible intervention for each jobseeker. The goal is to answer the question of 'what works for whom'.

Well documented early cases of systems following a particular targeting approach are the Service and Outcome Measurement System (SOMS) in Canada (Colpitts, 2002), parts of the Frontline Decision Support System (FDSS) in the US (Eberts et al., 2002), the Treatment Effects and Prediction (TrEffeR) system in Germany (Stephan et al., 2006), and the system for Statistically Assisted Programme Selection (SAPS) in Switzerland (Behncke et al., 2009). The models use similar variables as the profiling algorithms but estimate labour market outcomes conditional on potential interventions.

However, the SOMS, FDSS and SAPS were all discontinued and the TrEffeR system does not operate as an operative predictive algorithm but as an evaluation scheme (Büttner et al., 2015). Colpitts (2002) writes about the SOMS that the predictive algorithms were 'the system's Achilles' heel' (p. 291). He found that the predictive models often resulted in most of the clients being targeted to the same intervention and when testing different models, the models differed greatly in their recommendations. A general issue is the high number of programmes: in order to estimate effects, the programmes need to be grouped into categories such as 'com- 
puter training' and 'work experience' programmes. These broad categories, however, make the predictions less useful to caseworkers who want to know specifically which of the training or work experience programmes they should assign.

Recently, New Zealand introduced a targeting approach called the Service Effectiveness Model (Blakeley, 2018), however, little is known about the details of the predictive algorithm. Machine learning based approaches are described in, e.g., Knaus et al. (2022) and Cockx et al. (2020), but we are not aware of implementations in PES.

\subsection{Matching}

To match jobseekers to vacancies is one of the original functions of PES. The idea of matching with predictive algorithms is to predict the likelihood of a successful match between a jobseeker and a job. This serves two purposes: first, searching suitable jobs for each client is a timeconsuming task for caseworkers and predictive algorithms can be used to automatically filter a set of likely jobs from large databases, and second, predictive algorithms can recommend relevant jobs outside of the scope of the jobseekers' job search (Belot et al., 2019).

The VDAB in Belgium partnered with a private company to develop a job matching algorithm, known as JobNet (Klewais, 2017). The algorithm behind JobNet is reported to be a deep learning model that predicts the probability of a match from associations between keywords in the jobseekers' profiles and vacancy descriptions. Belot et al. (2019) estimate models on general population data to display alternative relevant occupations and associated jobs to jobseekers. They find that their recommendations broaden the job search and increase the number of job interviews. In France, a tool called Bob Emploi was developed jointly by the private nonprofit organisation Bayes Impact together with the French PES. Bob Emploi asks jobseekers online for information and then predicts the likelihood of finding a job in different sectors and different areas to guide the jobseekers to a job search strategy that increases their chances of finding a job. A large-scale evaluation, described in Ben Dhia et al. (2019), however, found that Bob Emploi had limited effects on job seekers' search strategy and no effect on reemployment outcomes. 
While theoretically the use of algorithms for matching is appealing, practical projects in PES are rare. This could be the result of several factors. One is that the field of matching has seen the launch of numerous private websites to bring jobs and jobseekers together (Ben Dhia et al., 2019). It could be that PES are not the predominant provider of this service anymore.

In order to evaluate the general state of predictive algorithms in PES, it is important to be clear about what they are and what they are not. In most studies the predictive performance was judged sufficiently to test the model in practice. This suggests that labour market outcomes are, to a large extent, a predictable phenomenon. With technical developments and the increasing availability of larger and wider data sets, the accuracy will likely further increase. However, an accurate prediction alone does not help jobseekers. PES and their caseworkers need to be able to use the predictions to make better decisions and, most importantly, need to provide effective services to help jobseekers back into employment. If, in the case of targeting, all programs have only moderate effects, selecting the best one of them with predictive algorithms cannot lead to large gains in labour market outcomes. Moreover, matching can only help if suitable jobs are available that the jobseekers can fill.

\section{Algorithmic fairness and discrimination}

PES allocate services to citizens, so it is natural that predictive algorithms supporting decisionmaking in PES raise concerns about fairness and discrimination (e.g., Pope and Sydnor, 2011; Allhutter et al., 2020; Desiere and Struyven, 2021; Kern et al., 2021). In this section, we will briefly discuss the general debate of algorithmic fairness and relate it to the use of predictive algorithms in PES. We argue that the use of predictions to allocate employment services should be accompanied by an explicit discussion of the policy objectives that are being pursued.

\subsection{Measures of (un)fairness}

Widespread concerns that predictive algorithms are reproducing and reinforcing discrimination against disadvantaged groups have led to an active research field on algorithmic fairness, defining various statistical measures of (un)fairness (see Verma and Rubin, 2018, for an overview). 
The predominant definitions measure inequalities in predicted outcomes or predictive performances for individuals who (only) differ on so called 'protected attributes' (race, gender, or another attribute that should not be discriminated against).

The spotlight fell on the field through the debate about a profiling tool for recidivism risk called COMPAS that is used by courts in several US states. Angwin et al. (2016) found that the tool's errors were asymmetric between African-American and white defendants and concluded that it was racially biased. Dieterich et al. (2016) raised objections to this conclusion because the predictive values were equally valid for both groups. The controversy highlighted what holds true for many definitions of fairness: except when base rates are equal or predictions are perfect, it is mathematically impossible to satisfy them simultaneously (Kleinberg et al., 2017; Chouldechova, 2017).

The incompatibility of fairness measures is also a result of differences in the underlying views about what constitutes a fair status quo and a fair allocation (of services in the case of PES). Kuppler et al. (2021) show that the appropriateness of the measures varies across distributive justice principles, and for some measures the underlying distributive justice principles is unclear: measures focusing on inequalities of error distributions may show problems in the predictions for one group, but it is unclear which principle of justice would be achieved by enforcing equality (see also Bansak and Martén, 2021). To make progress over fairness measures competing in the abstract, the policy objectives in the allocation of services have to be discussed more explicitly.

\subsection{Policy objectives}

PES cannot offer all employment services to everyone, so they must have some allocation mechanism to determine who participates and who does not. Different possible policy objectives such as equity, service to particular groups, or other distributive justice principles (see Kuppler et al., 2021, for a detailed discussion) and efficiency or budget considerations are in conflict with each other in the allocation (Berger et al., 2001). Predictive algorithms can predict expected labour outcomes (under present inequalities), they do not dictate the allocation (see also Corbett-Davies and Goel, 2018). The allocation of services should be guided by policy 
objectives that make progress from the current labour market (reflected in the predictions) to the desired one.

In the case of profiling, this might mean to directly follow the predictions, reflecting labour market discrimination, and direct attention to the jobseekers classified as 'high-risk'. ${ }^{3}$ A profiling tool has the objective of identifying jobseekers at risk of long-term unemployment, so discrimination as a result of employers' hiring behaviour is an important factor as it is a real obstacle to labour market re-entry (e.g., Bertrand and Mullainathan, 2004). In the case of targeting, a PES could also follow the predictions and maximise efficiency if this is the objective. Alternatively, an objective could be to target the jobseekers who are most in need (known from profiling) with beneficial interventions (known from targeting) (Berger et al., 2001), or PES decide to target the jobseekers first who would fall below a threshold of sufficient resources without help. In the case of matching, PES may want to weigh short term objectives in terms of quick labour market re-entry against longer term ones. Short-term, PES would want to direct jobseekers to likely jobs following the predictions and not encourage jobseekers to apply to jobs where they are likely to suffer from discrimination. Long-term, PES might want to do the opposite to reduce labour market segregation.

This brief discussion of algorithmic fairness and discrimination scratches the surface of the large body of literature that evolved over the last years. However, we show that fairness cannot only be considered in the abstract but the debate has to be held in close relationship with the policy objectives that are pursued.

\section{The caseworker in the loop}

The public debate about predictive algorithms is often framed as a question of humans against machines (e.g., Dressel and Farid, 2018; Lin et al., 2020). However, the ultimate choice and responsibility in policy applications of predictive algorithms in PES lies with the caseworkers. Caseworkers often have significant leeway in their work and the use of predictions is at their

\footnotetext{
${ }^{3}$ We assume here that receiving help is in the interest of the jobseeker, even though, as pointed out by Desiere and Struyven (2021) a 'high-risk' classification may not always be positive: being identified as a person at risk of long-term unemployment may also be associated with a more demanding activation path. It may also be the case that excessive participation in labour market programmes can be stigmatizing, resulting in a negative effect of receiving not needed help (Liechti et al., 2017).
} 
discretion (see Van Berkel, this volume, for more information on the role of caseworkers). Thus, the policy relevant question is: how do the two interact? (Stevenson and Doleac, 2019).

We will start by highlighting some observations about the interaction we made during the review of applications: Arni and Schiprowski (2015) report the results of the implementation of a profiling tool in the Swiss canton Fribourg and show that in contrast with expectations, caseworkers intensified their efforts for jobseekers who were classified as easy to place by the tool. This is the opposite of the intended use of the tool, which is to allow caseworkers to spend more time on those classified as difficult to place. Another finding of Arni and Schiprowski (2015) is the resistance of caseworkers to the implementation of the tool, a finding that is also reported by Barnes et al. (2015) for Denmark, where caseworkers collectively renounced a profiling tool because they felt uncomfortable having to justify their decision when they went against the recommendation of the profiling tool. Grundy (2015) reports reactions from caseworkers about the SOMS in Canada. Among them is a statement that decision-making 'depends on who the person in front of you is. What's their attitude like?', while another statement is reported as 'I deal with people, not statistics' (both on p. 57). He further reports the general fears of the technology's potential to deskill the work of the caseworkers. The observations suggest that the impact of predictive algorithms depends on how the caseworkers decide to use them and not necessarily on the expectations of the policy makers, and that caseworkers often resist predictive algorithms (see also Hasluck, 2008).

Lipsky (1980) describes that bureaucracies tend to measure performance to seek control and that the behavior of the caseworkers reflects the incentives and sanctions implicit in those measurements. He illustrates the argument with an example from Blau (1963): when PES began to evaluate their performance in terms of its placement rate, the caseworkers shifted their focus to the more easily employed at the expense of the more difficult to place. This could explain Arni and Schiprowski (2015)'s observation. ${ }^{4}$

Zacka (2018) builds on Lipsky (1980) and highlights different dimensions which streetlevel bureaucrats need to balance in their work: efficiency, fairness, responsiveness, and re-

\footnotetext{
${ }^{4}$ We could also hypothesise that this behaviour is related to defensive decision making (Gigerenzer, 2015): caseworkers might be concerned that if jobseekers with a prediction of quick labour market re-entry were to stay unemployed for long, they may be held responsible.
} 
spect. Predictive algorithms are primarily aimed at improving the efficiency which can lead to tension with regards to the other objectives. Van Lancker and Van Hoyweghen (2021) note that a substantial share of the variation in decision-making can be explained by characteristics of social professionals, including their welfare state attitudes and their perception of clients' deservingness. Caseworkers might have different fairness perceptions than reflected by the outcome of the algorithm but are no longer able to act on them because they would go against predictions. They also want to be responsive to react to factors specific to each case and find the best action for everyone. Algorithms could be used to limit the discretion of the caseworkers (although rarely done in practice) and limit their ability to be responsive. The last dimension, respect, might be reflected in the remark 'I deal with people, not statistics' (Grundy, 2015, p. 57). Caseworkers might see the use of a machines as generally disrespectful towards jobseekers. Efficiency in itself can also be a source of misalignment. Caseworkers often feel that the additional information they have, and that is not available to the algorithm, allows them to make better decisions (e.g., Petersen et al., 2021). This might be amplified by what Dietvorst et al. (2015) call 'algorithm aversion': humans lose confidence more quickly in algorithms than human after seeing them make the same mistake. Caseworkers might also resist the tool through the opposite mechanism. If they assume that an algorithm is more accurate, the efficiency dimension can lead to the fear of being marginalized.

\section{Conclusion}

In this chapter, we have provided an introduction to the use of predictive algorithms in the delivery of services in PES. The enthusiasm around AI is sometimes inattentive towards previous projects using predictive algorithms that might provide lessons by sharing the same promises and difficulties. Like many others, we see much potential for efficiency and efficacy gains by making better predictions. However, we also see issues that need to be given serious consideration.

First, PES operate in a context (the labour market) where various forms of inequality and discrimination exist. This is reflected in the data used to build a predictive algorithm and in its predictions. The extent to which predictive algorithms should reproduce or try to eliminate 
discrimination depends on the function they perform and on the policy objectives that are being pursued. The use of predictive algorithms should be accompanied by an explicit discussion about the objective in the allocation of services.

Second, the predictions need to be understood by caseworkers and translated into decisions. As a result, it is important to understand how caseworkers use the information and the advice provided by algorithms. How can human caseworkers at best integrate algorithmic predictions in their decision making? There is very little research explicitly targeting this question, but what we have discussed above suggests that the interface between the caseworkers and predictive tools may be a major potential source of problems, because of unwillingness or inability to use the information provided or even because of the fact that the information provided is used in unexpected ways.

At last, we want to highlight that every algorithm offers the possibility to bring expert knowledge into practice. The questions to which answers are needed to develop predictive algorithms are not new to policy researchers: how to predict labour market outcomes? What are the effects of labour market policies? How do jobseekers find jobs? These questions have been studied by policy researchers for decades. The introduction of predictive algorithms, or algorithms in general, can bring this knowledge into policy practice. 


\section{References}

Agrawal, A., Gans, J., and Goldfarb, A. (2018). Prediction machines: the simple economics of artificial intelligence. Harvard Business Press.

Allhutter, D., Cech, F., Fischer, F., Grill, G., and Mager, A. (2020). Algorithmic profiling of job seekers in Austria: how austerity politics are made effective. Frontiers in Big Data, 3:5.

Angwin, J., Larson, J., Mattu, S., and Kirchner, L. (2016). Machine bias. ProPublica. https://www.propublica.org/article/machine-bias-risk-assessments-in-criminal-sentencing.

Arni, P. and Schiprowski, A. (2015). Die Rolle von Erwartungshaltungen in der Stellensuche und der RAV-Beratung. Teilprojekt 2: Pilotprojekt Jobchancen-Barometer. Publikation Arbeitsmarktpolitik 43, State Secretariat for Economic Affairs (SECO).

Bansak, K. and Martén, L. (2021). Algorithmic decision-making, fairness, and the distribution of impact: Application to refugee matching in Sweden. PolMeth 2021.

Barnes, S.-A., Wright, S., Irving, P., and Deganis, I. (2015). Identification of latest trends and current developments in methods to profile jobseekers in european public employment services: final report. Directorate-General for Employment, Social Affairs and Inclusion, European Commission.

Behncke, S., Frölich, M., and Lechner, M. (2009). Targeting labour market programmes-results from a randomized experiment. Swiss Journal of Economics and Statistics, 145(3):221-268.

Belot, M., Kircher, P., and Muller, P. (2019). Providing advice to jobseekers at low cost: An experimental study on online advice. The Review of Economic Studies, 86(4):1411-1447.

Ben Dhia, A., Crepon, B., Mbih, E., Paul-Delvaux, L., Picard, B., and Pons, V. (2019). L'impact du site d'aide à la recherche d'emploi bob emploi: Résultats d'un essai randomisé contrôlé. Rapport réalisé par le Centre de Recherche en Economie et Statistiques (CREST).

Berger, M. C., Black, D., and Smith, J. A. (2001). Evaluating profiling as a means of allocating government services. In Lechner, M. and Pfeiffer, F., editors, Econometric Evaluation of Labour Market Policies, pages 59-84. Physica, Heidelberg.

Bertrand, M. and Mullainathan, S. (2004). Are Emily and Greg more employable than Lakisha and Jamal? a field experiment on labor market discrimination. American Economic Review, 94(4):991-1013.

Bimrose, J., Barnes, S., Brown, A., Hasluck, C., and Behle, H. (2007). Skills diagnostics and screening tools: A literature review. Research report, Warwick Institute for Employment Research. 
Black, D. A., Galdo, J., and Smith, J. A. (2007). Evaluating the worker profiling and reemployment services system using a regression discontinuity approach. American Economic Review, 97(2):104-107.

Black, D. A., Smith, J. A., Plesca, M., and Shannon, S. (2003). Profiling UI claimants to allocate reemployment services: evidence and recommendations for States. US Department of Labor, Employment and Training Administration.

Blakeley, N. (2018). Service effectiveness model (SEM). Official information response, Ministry of Social Development, New Zealand Government.

Blau, P. M. (1963). The Dynamics of Bureaucracy: A Study of Interpersonal Relations in two Government Agencies. Chicago: University of Chicago Press.

Blázquez, M. (2014). Skills-based profiling and matching in PES. Analytical paper, European Commission, Directorate-General for Employment, Social Affairs and Inclusion.

Boškoski, P., Perne, M., Rameša, M., and Boshkoska, B. M. (2021). Variational bayes survival analysis for unemployment modelling. Preprint, arXiv:2102.02295.

Breiman, L. (2001). Statistical modeling: The two cultures. Statistical Science, 16(3):199-231.

Büttner, T., Schewe, T., and Stephan, G. (2015). Wirkung Arbeitsmarktpolitischer Instrumente im SGB III: Maßnahmen auf dem Prüfstand. Research report, IAB-Kurzbericht.

Chouldechova, A. (2017). Fair prediction with disparate impact: A study of bias in recidivism prediction instruments. Big data, 5(2):153-163.

Cockx, B., Lechner, M., and Bollens, J. (2020). Priority to unemployed immigrants? a causal machine learning evaluation of training in Belgium. CESifo Working Papers.

Colpitts, T. (2002). Targeting reemployment services in Canada. In Eberts, R. W., O'Leary, C. J., and Wandner, S. A., editors, Targeting Employment Services., pages 283-302. W.E. Upjohn Institute for Employment Research Kalamazoo, Michigan.

Corbett-Davies, S. and Goel, S. (2018). The measure and mismeasure of fairness: A critical review of fair machine learning. Preprint, arXiv:1808.00023.

De Troya, Í. M. d. R., Chen, R., Moraes, L. O., Bajaj, P., Kupersmith, J., Ghani, R., Brás, N. B., and Zejnilovic, L. (2018). Predicting, explaining, and understanding risk of long-term unemployment. In 32nd Conference on Neural Information Processing Systems.

Desiere, S., Langenbucher, K., and Struyven, L. (2019). Statistical profiling in public employment services: An international comparison. OECD Social, Employment and Migration Working Papers, No. 224. 
Desiere, S. and Struyven, L. (2021). Using artificial intelligence to classify jobseekers: The accuracy-equity trade-off. Journal of Social Policy, 50(2):367-385.

Dieterich, W., Mendoza, C., and Brennan, T. (2016). COMPAS risk scales: Demonstrating accuracy equity and predictive parity. Northpoint Inc.

Dietvorst, B. J., Simmons, J. P., and Massey, C. (2015). Algorithm aversion: People erroneously avoid algorithms after seeing them err. Journal of Experimental Psychology: General, 144(1):114.

Dressel, J. and Farid, H. (2018). The accuracy, fairness, and limits of predicting recidivism. Science Advances, 4(1):eaao5580.

Eberts, R., O'Leary, C., and DeRango, K. (2002). A frontline decision support system for one-stop centers. In Eberts, R. W., O'Leary, C. J., and Wandner, S. A., editors, Targeting Employment Services., pages 337-380. W.E. Upjohn Institute for Employment Research Kalamazoo, Michigan.

Ferwerda, J., Adams-Cohen, N., Bansak, K., Fei, J., Lawrence, D., Weinstein, J. M., and Hainmueller, J. (2020). Leveraging the power of place: A data-driven decision helper to improve the location decisions of economic immigrants. Preprint, arXiv:2007.13902.

Frölich, M. (2008). Statistical treatment choice: an application to active labor market programs. Journal of the American Statistical Association, 103(482):547-558.

Frölich, M., Lechner, M., and Steiger, H. (2003). Statistically assisted programme selectioninternational experiences and potential benefits for Switzerland. Swiss Journal of Economics and Statistics, 139(3):311-331.

Gigerenzer, G. (2015). Risk savvy: How to make good decisions. Penguin.

Griffin, R., Tuite, A., Roche, Z., and Gallagher, P. (2020). Report ethical, social, theological, technical review of 1st generation PES algorithms and data use. Disruptive Technologies Supporting Labour Market Decision Making.

Grundy, J. (2015). Statistical profiling of the unemployed. Studies in Political Economy, 96(1):47-68.

Hasluck, C. (2008). The use of statistical profiling for targeting employment services: The international experience. In Di Domenico, G. and Spattini, S., editors, New European approaches to long-term unemployment: What role for public employment services and what market for private stakeholders? Kluwer Law International BV.

Hofman, J. M., Sharma, A., and Watts, D. J. (2017). Prediction and explanation in social systems. Science, 355(6324):486-488. 
Kern, C., Bach, R. L., Mautner, H., and Kreuter, F. (2021). Fairness in algorithmic profiling: A German case study. Preprint, arXiv:2108.04134.

Kleinberg, J., Lakkaraju, H., Leskovec, J., Ludwig, J., and Mullainathan, S. (2018). Human decisions and machine predictions. The Quarterly Journal of Economics, 133(1):237-293.

Kleinberg, J., Mullainathan, S., and Raghavan, M. (2017). Inherent trade-offs in the fair determination of risk scores. Proceedings of the 8th Conference on Innovations in Theoretical Computer Science (ITCS).

Klewais, E. (2017). Next steps at VDAB. Presentation, European Centre for the Development of Vocational Training (Cedefop).

Knaus, M. C., Lechner, M., and Strittmatter, A. (2022). Heterogeneous employment effects of job search programmes: A machine learning approach. Journal of Human Resources, pages 0718-9615R1.

Kuppler, M., Kern, C., Bach, R. L., and Kreuter, F. (2021). Distributive justice and fairness metrics in automated decision-making: How much overlap is there? Preprint, arXiv:2105.01441.

Liechti, F., Fossati, F., Bonoli, G., and Auer, D. (2017). The signalling value of labour market programmes. European Sociological Review, 33(2):257-274.

Lin, Z. J., Jung, J., Goel, S., and Skeem, J. (2020). The limits of human predictions of recidivism. Science Advances, 6(7):eaaz0652.

Lipp, R. (2005). Job seeker profiling: The Australian experience. Keynote EU-Profiling seminar.

Lipsky, M. (1980). Street-level bureaucracy: Dilemmas of the individual in public service. Russell Sage Foundation.

Lipton, Z. C. (2016). The deception of supervised learning. Knowledge Discovery Nuggets (KDnuggets).

Loxha, A. and Morgandi, M. (2014). Profiling the unemployed: a review of OECD experiences and implications for emerging economies. Social Protection and Labor Discussion Paper, 1424. World Bank Group, Washington, DC.

Mitchell, S., Potash, E., Barocas, S., D’Amour, A., and Lum, K. (2021). Algorithmic fairness: Choices, assumptions, and definitions. Annual Review of Statistics and Its Application, 8.

Mullainathan, S. and Spiess, J. (2017). Machine learning: an applied econometric approach. Journal of Economic Perspectives, 31(2):87-106. 
Petersen, A. C. M., Christensen, L. R., Harper, R., and Hildebrandt, T. (2021). "We would never write that down" classifications of unemployed and data challenges for AI. Proceedings of the ACM on Human-Computer Interaction, 5(CSCW1):1-26.

Pope, D. G. and Sydnor, J. R. (2011). Implementing anti-discrimination policies in statistical profiling models. American Economic Journal: Economic Policy, 3(3):206-31.

Schwanse, P. (1997). Activating the unemployed. The OECD Observer, 209:10-12.

Shmueli, G. (2010). To explain or to predict? Statistical Science, 25(3):289-310.

Stephan, G., Rässler, S., and Schewe, T. (2006). Das TrEffeR-Projekt der Bundesagentur für Arbeit: Die Wirkung von Maßnahmen aktiver Arbeitsmarktpolitik. Zeitschrift für ArbeitsmarktForschung-Journal for Labour Market Research, 39(3/4):447-465.

Stevenson, M. T. and Doleac, J. L. (2019). Algorithmic risk assessment in the hands of humans. Available at SSRN 3489440.

Van Berkel, R. (this volume). The changing role of frontline employment advisors. In Clegg, D. and Durazzi, N., editors, Research Handbook of Labour Market Policy in Rich Democracies. Edward Elgar Publishing.

Van Lancker, W. and Van Hoyweghen, I. (2021). Targeting in social security and healthcare: the promises and pitfalls of digital technologies. In Laenen, T., Meuleman, B., Otto, A., Roosma, F., and Van Lancker, W., editors, Leading Social Policy Analysis from the Front. KU Leuven. Centre for Sociological Research; Leuven.

Van Landeghem, B., Desiere, S., and Struyven, L. (2021). Statistical profiling of unemployed jobseekers: the increasing availability of big data allows for the profiling of unemployed jobseekers via statistical models. IZA World of Labor, 2021.

Verma, S. and Rubin, J. (2018). Fairness definitions explained. In 2018 ACM/IEEE International Workshop on Software Fairness, pages 1-7. IEEE.

Wandner, S. A., Messenger Jon, C., and Schwartz, S. (1999). Worker profiling and reemployment services policy workgroup: Final report and recommendations. Technical report, Employment and Training Administration (DOL), Washington, DC. Office of Policy and Research.

Weishaupt, T. (this volume). Public employment services: Mapping reform trends and organisational arrangements. In Clegg, D. and Durazzi, N., editors, Research Handbook of Labour Market Policy in Rich Democracies. Edward Elgar Publishing.

Zacka, B. (2018). When the state meets the street. Harvard University Press. 